\title{
EFEKTIVITAS INTERVENSI SPIRITUAL MANAGEMENT OF RELAXATION THERAPY (SMARTER) DALAM UPAYA MENCEGAH DEPRESI IBU POSTPARTUM
}

\author{
M. Ardan $\circledast^{1)}$, Zulkifli Umar $\left(^{2)}\right.$, Abd. Kadir $\oplus^{3)}$ dan Dwi Ryan Ariestantia $\bigoplus^{4)}$ \\ ${ }^{1,2,3}$ Administrasi Rumah Sakit, Sekolah Tinggi Ilmu Kesehatan Mutiara Mahakam Samarinda \\ ${ }^{4}$ Kebidanan, Sekolah Tinggi Ilmu Kesehatan Mutiara Mahakam Samarinda \\ 1,2,3,4J1. Ery Suparjan, No.49A, RT.12, Kel. Sempaja Selatan, Samarinda, 75119 \\ E-mail : ardan0410@gmail.com ${ }^{1)}$, zulkifliumar.arsmm@gmail.com ${ }^{2}$, abdkadir.ars@gmail.com ${ }^{3)}$, \\ dwi.riyanmelon@gmail.com ${ }^{4)}$
}

\begin{abstract}
ABSTRAK
Di Indonesia, 50-70\% wanita mengalami sindrom yang berkembang menjadi depresi postpartum dengan variasi sekitar 5\% sampai lebih dari $25 \%$ setelah melahirkan. Depresi postpartum adalah suatu keadaan seorang ibu merasa sedih, bersalah, dan bentuk depresi umum lainnya dalam waktu lama setelah melahirkan, hal ini dapat menyebabkan ketidakmampuan ibu untuk merawat dirinya dan bayinya, sehingga diperlukan upaya intervensi oleh tenaga kesehatan dalam memberikan pelayanan kesehatan ibu postpartum. Penelitian ini bertujuan untuk menganalisis efektivitas intervensi Spiritual Management of Relaxation Therapy (SMARTER) dalam upaya pencegahan depresi ibu nifas. Penelitian ini menggunakan desain penelitian quasi-experimental pre-test post-test with control group design yang dibagi menjadi 2 kelompok (17 responden pada kelompok intervensi dan 17 responden pada kelompok kontrol). Hasil uji normalitas data diperoleh data terdistribusi normal, sehingga hasil analisis menggunakan uji t berpasangan menunjukkan bahwa terjadi perbedaan tingkat depresi sebelum dan sesudah intervensi SMARTER pada kelompok intervensi ( $p$-value-0,000) dan control ( $p$-value 0,004), sedangkan hasil analisis menggunakan uji t tidak berpasangan menunjukkan bahwa terdapat perbedaan tingkat depresi sesudah intervensi SMARTER antara kelompok intervensi dan kontrol dengan nilai $p$-value 0,000. Penelitian ini juga dapat memberikan rekomendasi kepada tenaga kesehatan khususnya bidan agar dapat memberikan pelayanan berupa pelayanan asuhan yang komplementer.
\end{abstract}

Kata Kunci: Ibu Postpartum, Depresi, Perawatan, Kontemporer, Smarter

\section{PENDAHULUAN}

Depresi adalah suatu bentuk gangguan suasana hati yang mempengaruhi kepribadian seseorang, juga sinonim dengan perasaan sedih, murung, kesal, tidak bahagia dan menderita. Sedangkan depresi postpartum merupakan kondisi yang dapat terjadi oleh perempuan pada periode pasca persalinan. Tidak seseorang pun yang menduga akan mengalami hal tersebut, karena pada umumnya perempuan yang hamil, terutama yang pertama kali, tentu sangat menantikan kehadiran bayinya (Hanifah \& Kusumawati, 2017). Depresi postpartum juga merupakan istilah yang digunakan pada pasien yang mengalami berbagai gangguan emosional yang timbul setelah melahirkan, khususnya pada gangguan depresi spesifik terjadi pada $10-15 \%$ wanita pada tahun pertama setelah melahirkan serta mempengaruhi $17,7 \%$ dari populasi wanita secara global (Hahn-Holbrook et al., 2018). Di Indonesia sekitar 50-70\% wanita mengalami syndrome dan hal ini dapat berlanjut menjadi depresi postpartum dengan jumlah bervariasi dari 5\% hingga lebih dari 25\% setelah ibu melahirkan (Asmayanti, 2017). Penelitian sebelumnya telah mengidentifikasi berbagai faktor risiko depresi pasca partum seperti depresi antenatal, kecemasan, peristiwa kehidupan yang penuh tekanan (Norhayati, 2015; Yim, 2015), dan faktorfaktor yang berhubungan dengan depresi postpartum $\leq 1$ tahun pasca persalinan seperti ketimpangan pendapatan (Hanifah \& Kusumawati, 2017). Depresi postpartum merupakan masalah kesehatan masyarakat yang utama (Wisner et al., 2016). Hal tersebut dapat menimbulkan konsekuensi buruk yang serius bagi para ibu, meningkatkan tantangan untuk merawat secara bersamaan keturunan, menangani tugas rumah tangga, serta tugas pekerjaan (O'Hara, 2009). Apalagi, ibu depresi postpartum dapat menimbulkan konsekuensi serius bagi fisik, emosional dan kognitif perkembangan serta untuk perilaku anak (L Murray et al., 2010; S Farías-Antúnez et al., 2018).

Hasil penelitian sebelumnya menunjukkan bahwa sebagian besar wanita mengalami gangguan emosional pasca melahirkan, hal ini sejalan dengan penelitian yang menunjukkan bahwa setelah dilakukan intervensi CBT depresi ibu postpartum mengalami perubahan dari 15 responden yang mengalami depresi menjadi 3 responden yang depresi (Girsang, 2013). Selain itu juga penelitian lainnya menunjukkan bahwa penanganan psikologis dalam bentuk terapi kognitif dan perilaku pada ibu bersalin dapat mereduksi terjadinya depresi postpartum 
(Chen et al., 2000). Intervensi non farmakologi juga dapat membuat ibu hamil merasa lebih tenang, nyaman, dan rileks dalam mengurangi tingkat kecemasan, dengan tambahan sentuhan freedom technique membuat ibu hamil menjadi lebih baik dan lebih rileks (Susilowati et al., 2019). Hal ini juga sejalan dengan penelitian lainnya yang menujukkan bahwa terapi zikir mampu menurunkan tingkat stress (Safitri et al., 2017). Hasil dalam penelitian lainnya juga membuktikan bahwa terapi murotal Al-Qur'an mampu menurunkan kecemasan ibu hamil, serta dalam menghadapi kecemasan dapat diturunkan dengan metode Spiritual Emotional Freedom Technique (Budiyarti \& Makiah, 2018; Yuniarsih, 2018). Mempertimbangkan efek merugikan dari depresi postpartum, perlu upaya penelitian lebih lanjut agar mampu meningkatkan kesehatan dan kesejahteraan secara keseluruhan keluarga. Terutama dalam upaya pencegahan secara dini melalui pengembangan terapi kontemporer, karena dapat menjadi sasaran langsung oleh pelayanan kesehatan dan oleh karena itu meringankan beban depresi postpartum relatif mudah, salah satunya dengan metode Spiritual Management of Relaxation Therapy (SMARTER).

SMARTER merupakan sebuah metode yang digunakan dalam bentuk penyembuhan dengan distraksi secara nonfarmakologis untuk mengobati atau mengurangi berbagai macam keluhan baik fisik dan psikologis. SMARTER dikembangkan dengan memadukan berbagai metode diantaranya Spiritual Emotional Freedom Technique (SEFT) dan Pencerahan Qolbu Padang Lampe (PQPL) guna memberikan edukasi dan pelayanan kepada masyarakat untuk memberikan rasa rileks, rasa tenang, serta merasa bersemangat kembali dengan memberikan gerakan-gerakan sederhana yang dilakukan untuk membantu menyelesaikan masalah sakit fisik maupun psikis, meningkatkan kinerja serta meraih kedamaian hidup (Gobel, 2019; Zainuddin, 2014). Selain itu SMARTER juga menggabungkan antara energi spiritual dan energi psikologi yang menghubungkan dengan manusia dengan Tuhannya. Hal ini dilakukan dalam bentuk doa dan zikir serta kepercayaan dengan penuh kesadaran yang mengandung unsur spiritual untuk membangkitkan harapan, rasa percaya diri sehingga mempercepat penyelesaian masalah fisik maupun psikis pasien, sehingga hal ini dapat dilakukan di berbagai pelayanan kesehatan.

Berdasarkan latar belakang diatas yang telah diuraikan maka menjadi dasar peneliti untuk menganalisis efektivitas intervensi Spiritual Management of Relaxation Therapy (SMARTER) dalam upaya mencegah depresi ibu postpartum di Klinik Kota Samarinda.

\section{RUANG LINGKUP}

Cakupan permasalahan dalam penelitian ini adalah untuk menganalisis efektivitas dari metode SMARTER dalam upaya menurunkan tingkat depresi pada Ibu Postpartum. Penelitian ini terbatas pada metode intervensi yang diberikan kepada 1 kelompok dan dibandingkan terhadap kelompok lainnya yang tidak diberikan perlakuan SMARTER, selain itu hanya diberikan kepada ibu Postpartum yang mengalami tingkat depresi gangguan mood ringan, batas depresi borderline dan depresi sedang. Target rencana yang ingin dicapai adalah menurunnya tingkat depresi bagi ibu dan meningkatnya derajat kesehatan masyarakat khususnya ibu pasca melahirkan serta diperoleh metode kontemporer yang dapat digunakan secara komprehensif dalam memberikan asuhan kebidanan.

\section{BAHAN DAN METODE}

Jenis penelitian ini adalah kuantitatif menggunakan rancangan penelitian Quasi Eksperimen pre and post with control group design. Penelitian ini diambil sebanyak 34 sampel untuk kedua kelompok (17 responden kelompok intervensi dan 17 responden kelompok kontrol) dengan teknik purposive sampling yang memiliki kriteria inklusi: 1). Menetap di wilayah Kota Samarinda dan bersedia menjadi responden; 2). Melahirkan aterm (37-42 minggu); 3). Kehamilan tunggal; 4). Kehamilan yang diinginkan ibu, 5). Ibu mengalami gejala depresi ringan hingga sedang. Sedangkan kriteria eksklusi sebagai berikut: 1). Ibu tidak dapat berkomunikasi dengan baik; 2). Ibu mengalami gangguan mental atau depresi berat.

Kelompok intervensi dan kelompok kontrol yang sesuai dengan kriteria inklusi dianalisis tingkat depresi nya menggunakan kuesioner Beck Depression Inventory, kemudian kelompok intervensi diberikan perlakuan dengan menggunakan metode SMARTER kepada responden ibu postpartum yang mengalami tingkat depresi (gangguan mood ringan, batas depresi borderline dan atau depresi sedang). Metode SMARTER diberikan melalui tahapan-tahapan yang terstruktur sesuai panduan dimulai dengan mengajak ibu postpartum dengan kondisi rileksasi, mendengarkan ayat-ayat suci alqur'an dan/atau bersumber dari kitab suci injil sesuai agama ibu selama 5 menit dengan volume tidak terlalu keras, lalu memutarkan instrument relaksasi sekitar 3 menit, selanjutnya fasilitator mengajak ibu postpartum untuk memuji kecantikan sang buah hati dengan karunia Tuhan Yang Maha Esa, menyemangati dan memotivasi ibu yang telah menjadi seorang ibu untuk putra putrinya, setelah itu melakukan sentuhan titik-titik meridian ibu menggunakan konsep Emotional Freedom Technique selama 3 menit, selain Metode SMARTER, ibu postpartum juga diberikan buku bacaan tentang perubahan fisiologis dan psikologis ibu postpartum. Sedangkan kelompok kontrol hanya diberikan bahan bacaan. Setelah diberikan perlakuan intervensi kemudian kedua kelompok diberikan kembali kuesioner yang sama untuk melihat tingkat depresi ibu postpartum. Kedua kelompok tidak dilakukan pre-test maupun post-test secara bersamaan disebabkan waktu kunjungan/partus ibu dihari yang berbeda-beda, namun seluruh sampel diambil dalam waktu rentang yang sama yakni mulai 
pada tanggal 01 Juni 15 Juli 2021 di tempat klinik yang sama. Pelaksanaan post-test dilakukan 30 menit setelah pelaksanaan metode SMARTER dengan menggunakan kuesioner yang sama.

Karakteristik data responden yang dikumpulkan pada penelitian ini adalah : Umur Ibu, Pekerjaan Ibu, Pendidikan Ibu, Paritas dan tingkat depresi dari Ibu Postpartum. Tingkat depresi ibu postpartum diambil dengan menggunakan kuesioner Beck Depression Inventory yang tervalidasi, responden akan mengisi kuesioner sesuai dengan perasaan yang dihadapi ibu yang tertera pada kuesioner, selanjutnya peneliti melakukan Analisis tingkat depresi ibu postpartum. BDI merupakan alat ukur yang dapat dipercaya untuk mendeteksi ada atau tidaknya depresi serta dapat memperlihatkan tingkat parah nya penderitanya. Para responden akan mengisi 21 pertanyaan, setiap pertanyaan memiliki skor $0 \mathrm{~s} / \mathrm{d} 3$, setelah responden menjawab semua pertanyaan kemudian menjumlahkan skor tersebut, Skor tertinggi adalah 63 jika responden mengisi 3 poin keseluruhan pertanyaan. Skor terendah adalah 0 jika responden mengisi poin 0 pada keseluruhan pertanyaan. Kriteria objektif untuk tingkat depresi adalah : 0-10 (normal), 11-16 (gangguan mood ringan), 17-20 (batas depresi borderline), 21-30 (depresi sedang), 31-40 (depresi berat dan 41-63 (depresi ekstrem).

Analisis data dilakukan terlebih dahulu dengan melihat distribusi normal dari setiap data. Jika data terdistribusi normal maka untuk menguji perbedaan pada suatu kelompok pre-post menggunakan uji $\mathrm{T}$ berpasangan sedangkan untuk melihat efektivitas intervensi menggunakan uji t tidak berpasangan dengan nilai alpha $\alpha=0,05$.

Bahan dan metode penelitian ini pada gambar 1.

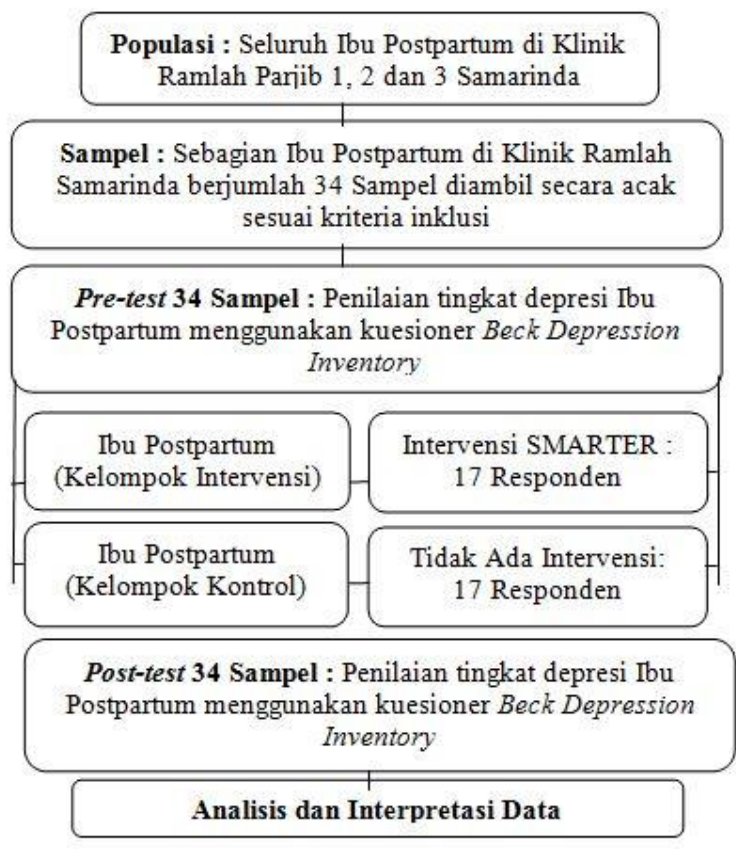

Gambar 1. Alur, Bahan, dan Metode Penelitian

\section{PEMBAHASAN}

SMARTER merupakan sebuah metode kontemporer pelayanan kesehatan yang dapat memberikan edukasi serta rasa tenang dan percaya diri pada diri seseorang agar dapat menjadi lebih rileks dan semangat sehingga penelitian ini memperoleh hasil sebagai berikut:

\subsection{Karakteristik Responden}

Karakteristik responden merupakan gambaran objek penelitian yang diberikan perlakuan untuk menghasilkan sebuah gambaran data responden yang diambil. Karakteristik dalam penelitian ini diantaranya umur, pekerjaan, pendidikan dan paritas. Hasil dari data karakteristik responden pada tabel 1.

Tabel 1. Hasil Analisis Berdasarkan Karakteristik Responden pada Kelompok Intervensi dan Kelompok Kontrol

\begin{tabular}{|l|c|c|c|c|}
\hline \multirow{2}{*}{$\begin{array}{c}\text { Karakteristik } \\
\text { Responden }\end{array}$} & \multicolumn{2}{c|}{$\begin{array}{c}\text { Kelompok } \\
\text { Intervensi }\end{array}$} & \multicolumn{2}{c|}{$\begin{array}{c}\text { Kelompok } \\
\text { Kontrol }\end{array}$} \\
\cline { 2 - 5 } & $\mathbf{n}$ & \% & n & \% \\
\hline Umur & & & & \\
17-25 tahun & 4 & 23,5 & 5 & 29,4 \\
26-35 tahun & 10 & 58,8 & 11 & 64,7 \\
$>35$ tahun & 3 & 17,6 & 1 & 5,8 \\
\hline Pekerjaan & & & & \\
PNS & 3 & 17,6 & 4 & 23,5 \\
Pegawai Swasta & 3 & 17,6 & 2 & 11,8 \\
Wiraswasta & 4 & 23,5 & 3 & 17,6 \\
IRT & 7 & 41,2 & 8 & 47,1 \\
\hline Pendidikan & & & & \\
Tamat SD & 1 & 5,8 & 1 & 5,8 \\
SMP & 8 & 11,8 & 1 & 5,8 \\
SMA & 6 & 47,1 & 8 & 47,1 \\
Tamat PT & & & & \\
\hline Paritas & 2 & 11,8 & 3 & 17,6 \\
Primipara & 12 & 70,6 & 13 & 76,5 \\
Multipara & 2 & 11,8 & 1 & 5,8 \\
Grandemultipara & & & \multicolumn{2}{|c}{} \\
\hline
\end{tabular}

Tabel 1. menunjukkan bahwa karakteristik umur responden penelitian pada didominasi usia produktif 26 35 tahun sebanyak 10 responden $(58,8 \%)$ dan pada kelompok intervensi dan 11 responden $(64,7 \%)$ pada kelompok kontrol. Distribusi terhadap karakteristik pekerjaan responden penelitian didominasi pada Ibu Rumah Tangga 41,2\% kelompok intervensi dan 47,1\% kelompok kontrol. Pada tabel tersebut juga menunjukkan bahwa pendidikan responden rata-rata berpendidikan Sekolah Menengah Atas (SMA) dan Pendidikan Tinggi diantaranya $47,1 \%$ (SMA) dan $35,3 \%$ (PT) pada kelompok intervensi sedangkan pada kelompok kontrol sebanyak 47,1\% (SMA) dan 41,2\% (PT). Paritas atau jumlah ibu melahirkan dari data tersebut menggambarkan bahwa rata-rata responden dengan paritas multipara atau telah melahirkan 2-5 orang anak pada kelompok intervensi sebesar 70,6\% dan 76,5\% pada kelompok kontrol. 


\subsection{Perbedaan Pre-test dan Post-test Depresi Ibu Postpartum Kelompok Intervensi}

Pre-test dan post-test merupakan kegiatan membandingkan nilai rata-rata perubahan nilai hasil data yang diperoleh kemudian dianalisis dan di interpretasikan sehingga memberikan gambaran tentang signifikan dari penelitian yang dilakukan. Berikut merupakan gambaran nilai perbedaan tingkat depresi Ibu Postpartum pada kelompok intervensi Smarter.

\section{Tabel 2. Perbedaan Tingkat Depresi Ibu Postpartum Sebelum dan Sesudah Intervensi SMARTER pada Kelompok Intervensi}

\begin{tabular}{|l|c|c|c|}
\hline \multirow{2}{*}{$\begin{array}{l}\text { Tingkat Depresi } \\
\text { Ibu Postpartum }\end{array}$} & \multicolumn{2}{|c|}{$\begin{array}{r}\text { Kelompok Intervensi } \\
\text { SMARTER }\end{array}$} & \multirow{2}{*}{ P value } \\
\cline { 2 - 3 } & Pre-test & Post-test & \\
\hline $\begin{array}{l}\text { Gangguan Mood } \\
\text { Ringan }\end{array}$ & $4(23,5 \%)$ & $11(64,7 \%)$ & \\
\hline $\begin{array}{l}\text { Batas Depresi } \\
\text { Borderline }\end{array}$ & $7(41,2 \%)$ & $5(29,4 \%)$ & \multirow{2}{*}{0,000} \\
\hline Depresi Sedang & $6(35,3 \%)$ & $1(5,9 \%)$ & \\
\hline
\end{tabular}

Berdasarkan hasil analisis pada tabel 2 diatas menunjukkan bahwa tingkat depresi responden pada saat pre-test sebagian besar mengalami gejala dengan batas depresi borderline sebanyak 7 (41,2\%) sedangkan setelah dilakukan intervensi SMARTER tingkat depresi ibu postpartum mengalami perubahan menurun menjadi gangguan mood ringan sebanyak $11(64,7 \%)$ kemudian yang mengalami depresi sedang hanya ada 1 responden sebesar $(5,9 \%)$. Tabel ini juga menunjukkan bahwa terdapat perbedaan rata-rata dengan nilai $\mathrm{p}$ value 0,000 .

\subsection{Perbedaan Pre-test dan Post-test Depresi Ibu Postpartum Kelompok Kontrol}

Kelompok kontrol merupakan kelompok pembanding untuk mengetahui efektivitas eksperimen dari sebuah metode yang diberikan. Pada kelompok ini tidak diberikan intervensi namun dilakukan sebuah pre-test dan post-test yang sama diberikan kepada kelompok intervensi. Berikut adalah hasil perbedaan tingkat depresi pre-test dan post-test Ibu postpartum pada kelompok kontrol.

Tabel 3. Perbedaan Tingkat Depresi Ibu Postpartum Sebelum dan Sesudah Intervensi SMARTER pada Kelompok Kontrol

\begin{tabular}{|c|c|c|c|}
\hline \multirow{2}{*}{$\begin{array}{l}\text { Tingkat Depresi } \\
\text { Ibu Postpartum }\end{array}$} & \multicolumn{2}{|c|}{ Kelompok Kontrol } & \multirow{2}{*}{$\begin{array}{c}P \\
\text { value }\end{array}$} \\
\hline & Pre-test & Post-test & \\
\hline $\begin{array}{l}\text { Gangguan Mood } \\
\text { Ringan }\end{array}$ & $5(29,4 \%)$ & $6(35,3 \%)$ & \multirow{3}{*}{0,004} \\
\hline $\begin{array}{l}\text { Batas Depresi } \\
\text { Borderline }\end{array}$ & $7(41,2 \%)$ & $6(35,3 \%)$ & \\
\hline Depresi Sedang & $5(29,4 \%)$ & $5(29,4 \%)$ & \\
\hline
\end{tabular}

Berdasarkan hasil analisis pada tabel 3 diatas menunjukkan bahwa tingkat depresi responden pada saat pre-test sebagian besar mengalami gejala dengan batas depresi borderline sebanyak $7(41,2 \%)$. Sedangkan pada saat dilakukan post-test responden yang mengalami gangguan mood ringan dan batas depresi borderline masing-masing 6 $(35,3 \%)$ responden kemudian tingkat depresi sedang pre-test maupun post-test tetap sebesar 5 responden atau sebesar $29,4 \%$. Tabel ini juga menunjukkan bahwa terdapat perbedaan rata-rata dengan nilai $p$ value 0,004 .

\subsection{Efektivitas Intervensi SMARTER Dalam Upaya Pencegahan Depresi Ibu Postpartum}

Efektivitas intervensi merupakan gambaran hasil sebuah penelitian yang telah dilaksanakan. Efektivitas intervensi memberikan gambaran apakah terdapat pengaruh atau tidak dari sebuah metode yang diujikan. Berikut merupakan hasil interpretasi data pada kelompok intervensi dan kelompok kontrol dalam menganalisis efektivitas intervensi:

Tabel 4. Perbedaan Tingkat Depresi Ibu Postpartum Sesudah Intervensi SMARTER pada Kelompok Intervensi Dibandingkan dengan Kelompok Kontrol

\begin{tabular}{|l|c|c|}
\hline \multirow{2}{*}{\multicolumn{1}{|c|}{ Statistik }} & \multicolumn{3}{|c|}{ Sesudah Intervensi } \\
\cline { 2 - 3 } & Mean & SD \\
\hline $\begin{array}{l}\text { Kelompok Intervensi } \\
\text { SMARTER }\end{array}$ & 12,10 & 2,2 \\
\hline Kelompok Kontrol & 18,88 & 4,1 \\
\hline Nilai $P$ value & \multicolumn{2}{|c|}{0,000} \\
\hline
\end{tabular}

Berdasarkan hasil analisis pada tabel 4. diatas menunjukkan bahwa hasil post-test menunjukkan bahwa rata-rata nilai memiliki perbedaan dan nilai $\mathrm{p}$ value juga menunjukkan sebesar 0,000 yang berarti intervensi SMARTER dapat mempengaruhi tingkat depresi ibu Postpartum.

Masa nifas atau postpartum telah menjadi tahapan yang sangat penting setelah melahirkan, pada masa ini dokter kandungan, bidan, ibu hamil menjadikan salah satu perhatian khusus. Selama kehamilan dan persalinan, wanita bersalin sering mengalami perubahan fisik maupun psikis sehingga dapat mengakibatkan kemungkinan masalah mental (Liu \& Yang, 2021; Rusner et al., 2016). Penelitian sebelumnya menunjukkan bahwa karena adanya perubahan mendadak setelah melahirkan ditambah dengan adanya perubahan dalam hubungan dan fungsi sosial akan menambah emosi seperti kecemasan dan depresi yang dapat mengalah kepada mental yang tidak sehat (Xu et al., 2017). Dalam penelitian lainnya dilakukan pengamatan selama 6 minggu pasca persalinan ditemukan tingkat depresi ibu yang cukup tinggi, namun dalam penelitian tersebut mengungkapkan bahwa adanya kemungkinan juga depresi dapat terjadi di dalam minggu pertama (Yamashita \& Yoshida, 2013). Depresi postpartum akan dapat berkurang setelah 1 tahun, namun diantaranya masih terdapat ibu yang tetap depresi untuk waktu yang cukup lama bahkan bisa menjadi lebih parah, hal ini akan dapat mempengaruhi efek samping yang lebih parah (Sebela et al., 2018).

Spiritual Management of Relaxation Therapy merupakan sebuah metode yang digunakan dalam bentuk penyembuhan dengan distraksi secara non farmakologis 
untuk mengobati atau mengurangi berbagai macam keluhan baik fisik dan psikologis. SMARTER dikembangkan dengan memadukan berbagai metode diantaranya Spiritual Emotional Freedom Technique (SEFT) dan Pencerahan Qolbu Padang Lampe (PQPL) guna memberikan edukasi dan pelayanan kepada masyarakat untuk memberikan rasa rileks, rasa tenang, serta merasa bersemangat kembali dengan memberikan gerakan-gerakan sederhana yang dilakukan untuk membantu menyelesaikan masalah sakit fisik maupun psikis, meningkatkan kinerja serta meraih kedamaian hidup.

Spiritual memotivasi manusia untuk mencari arti dan tujuan hidup. Spiritual merupakan "roh" yang menyintesis kepribadian dan mengarahkan energi untuk menjadi lebih tertib. Dimensi spiritual tidak dapat dipisahkan dari jiwa dan tubuh, melainkan memberikan kekuatan integrative. spiritualist mempengaruhi dan dipengaruhi oleh keadaan fisik, perasaan, pikiran dan hubungan antara ketiganya (Xu et al., 2017). Manajemen spiritual dapat dilakukan dalam 3 (tiga) tahapan diantaranya: 1). Menanamkan bahwa Allah SWT Maha Pengasih dan Maha Penyayang; 2). Memotivasi bahwa setiap manusia pasti memiliki kelebihan dan kekurangan. Pemberdayaan spiritual dan penyelarasan sistem energi tubuh untuk mengatasi masalah fisik (seperti sakit kepala yang berkepanjangan, nyeri punggung, alergi, asma, mudah letih, dan lain sebagainya), dan mengatai masalah emosional (trauma, depresi, phobia, stress, sulit tidur, bosan, malas, gugup, cemas, emosi, tidak percaya diri, dan lain sebagainya.

Intervensi SMARTER pada penelitian ini yang merupakan penggabungan antara terapi spiritual pencerahan qolbu (Gobel, 2019) dan Emotional Freedom Technique (Zainuddin, 2014) dalam memberikan perawatan ibu postpartum menghasilkan hasil yang cukup signifikan terhadap perubahan tingkat depresi ibu. Terapi spiritual menimbulkan respond yang cukup baik yang berdampak pada relaksasi dan kesehatan, hal ini akan memberikan rasa yakin dalam perawatan diri sehingga rasa cemat dan khawatir pada diri sendiri akan semakin berkurang dan menerima keadaan, dengan adanya bimbingan spiritual ini akan meningkatkan motivasi, semangat serta gejala fisik akan membuat kesehatan menjadi semakin baik yang berhubungan dengan depresi (Bakara, 2013). Kepercayaan spiritual termasuk di dalamnya keyakinan terhadap ajaran agama akan membentuk konsep seseorang tentang sehat. Hal ini akan dipengaruhi oleh adanya keyakinan bahwa setiap sesuatu yang terjadi adalah atas kehendak Tuhan Yang Maha Esa yang harus diterima dan disyukuri sehingga tingkat putus asa dan rasa tidak percaya diri akan berkurang seiring dengan adanya motivasi spiritual yang diberikan (Liu \& Yang, 2021; Rusner et al., 2016). Pasien akan merasa lebih rileks dan mampu menghadapi situasi yang dialami pasca persalinan karena adanya energi positif dalam bentuk afirmasi terhadap sentuhansentuhan pada diri pasien (Roacky \& Aini F, 2015), hal ini dilakukan dengan cara melakukan terapi kepada pasien untuk memberikan energi psikologis dengan mengedepankan atau memanfaatkan yang ada dalam tubuh manusia itu sendiri sehingga kekuatan dari dalam diri pasien akan lebih bersemangat.

Dalam studi lain menunjukkan bahwa peningkatan perawatan kesehatan mental untuk pasien postpartum secara efektiv mengurangi skor skala penilaian dari depresi ke skor skala penilaian kecemasan serta meningkatkan kualitas hidup pasien postpartum (Chen $\mathrm{H}$ et al., 2011).

\section{KESIMPULAN}

Hasil analisis data menunjukkan bahwa terdapat perbedaan penurunan tingkat depresi ibu postpartum sebelum dan sesudah intervensi SMARTER. Pada kelompok intervensi didominasi ibu postpartum yang mengalami gejala dengan batas depresi borderline dan setelah intervensi SMARTER berubah menjadi gangguan mood ringan. Sedangkan pada kelompok kontrol tingkat kecemasannya tetap pada level batas depresi borderline. Penelitian ini juga dapat memberikan rekomendasi kepada petugas kesehatan khususnya bidan agar dapat memberikan pelayanan dalam bentuk pelayanan asuhan kontemporer.

\section{SARAN}

Hasil dari penelitian ini diharapkan untuk dapat dikembangkan dan dilakukan penelitian dengan metode yang sama untuk ibu hamil trimester 3 (tiga) serta kepada wanita yang pertama hamil sehingga asuhan kontemporer ini dapat diterapkan secara komprehensif dalam asuhan kebidanan.

\section{DAFTAR PUSTAKA}

Asmayanti. (2017). Hubungan Dukungan Suami Dengan Kejadian Depresi Postpartum Di Rsud Panembahan Senopati Bantul Yogyakarta. Universitas Jendral Achmad Yani.

Bakara, D. (2013). Efek Spiritual Emotional Freedom Tecnique Terhadap Cemas dan Depresi Sindrom Koroner Akut. Buletin Peneltian Sistem Kesehatan.

Budiyarti, Y., \& Makiah. (2018). Murottal Al Qur' an Therapy Effect on Ansiety Level of Third Trimester Primigravida Pregnant Women. Jurnal Citra Keperawatan, 89-99.

Chen, C., Tseng, Y., Chou, F., \& Wang, S. (2000). Effects of support group intervention in postnatally distressed women. A controlled study in Taiwan. Journal Psychosom Res, 49(6), 395-399.

Chen H, J, W., Ch'ng, Y., Mingoo, R., Lee, T., \& Ong, J. (2011). . Identifying mothers with postpartum depression early: integrating perinatal mental health care into the obstetric setting. ISRN Obstet Gynecol.

Girsang, B. M. (2013). Pengobatan Perilaku Kognitif untuk Depresi Postpartum Cognitive Behavior Therapy for Postpartum Depression. Jurnal 
Kesehatan Masyarakat Nasional, 8, 9-12.

Gobel, F. A. (2019). Pendekatan Pencerahan Qolbu Untuk Kesehatan Odha. Leutikaprio.

Hahn-Holbrook, J., Cornwell-Hinrichs, T., \& Anaya, I. J. F. I. P. (2018). Economic And Health Predictors Of National Postpartum Depression Prevalence: A Systematic Review, Meta-Analysis, And MetaRegression Of 291 Studies From 56 Countries.

Hanifah, R. S., \& Kusumawati, S. Y. (2017). FaktorFaktor Yang Berhubungan Dengan Kejadian Depresi Postpartum Di Wilayah Kerja Puskesmas Karanganyar Kabupaten Karanganyar Tahun 2017. Universitas Muhammadiyah Surakarta.

L Murray, Hallingan, S., \& Cooper, P. (2010). Effects Of Postnatal Depression On Mother- Infant Interactions And Child Development. 2, 192-220.

Liu, H., \& Yang, Y. (2021). Efects of a psychological nursing intervention on prevention of anxiety and depression in the postpartum period: a randomized controlled trial. Annals of General Psychiatry, 20(2), 1-7.

Norhayati, M. (2015). Magnitude And Risk Factors For Postpartum Symptoms: A Literature Review. 3452.

O'Hara, M. (2009). Postpartum Depression: What We Know. 12, 1258-1269.

Roacky, H., \& Aini F. (2015). Pengaruh SEFT terhadap tekanan darah penderita hipertensi. Jurnal Keperawatan Sudirman

Rusner, M., Berg, M., \& C Begley. (2016). Bipolar disorder in pregnancy and childbirth: a systematic review of outcomes. BMC Pregnancy Childbirth, 19(1), 331.

S Farías-Antúnez, Xavier, M., \& Santos, I. (2018). Effect Of Maternal Postpartum Depression On Offspring's Growth. 228, 143-152.

Safitri, Nashori, H., \& Sulistyarini, I. (2017). Efektivitas Relaksasi Zikir Untuk Menurunkan Tingkat Stres Pada Penderita Diabetes Melitus Tipe Ii Relaxation With Dhikr To Decrease Stress Among Type Ii
Diabetes Patients. Jurnal Intervensi Psikologi, 9(1), 1-15

Sebela, A., Hanka, J., \& Mohr, P. (2018). Etiology, risk factors, and methods of postpartum depression prevention. . . Ceska Gyneko, 83(468-473).

Susilowati, Pramana, N., \& Muis, S. F. (2019). Intervensi Non Farmakologi Terhadap Kecemasan Pada Primigravida. Jurnal Ilmu Permas STIKES Kendal, 9, 181-186.

Wisner, K. L., Chambers, C., Sit, D., \& Jama. (2016). Postpartum Depression: A Major Public Health Problem. 21, 2616-2618.

Xu, H., Ding, Y., Ma, Y., Xin, X., \& Zhang, D. (2017). Cesarean section and risk of postpartum depression: a meta-analysis. J Psychosom Re, 97, $118-126$.

Yamashita, H., \& Yoshida, K. (2013). : Screening and intervention for depressive mothers of new-born infants. Seishin Shinkeigaku Zasshi, 1129-1135.

Yim, I. S. (2015). Biological And Psychosocial Predictors Of Postpartum Depression: Systematic Review And Call For Integration. 11.

Yuniarsih, S. (2018). Penggunaan SEFT ( Spiritual Emotional Freedom Technique ) untuk membantu Ibu hamil menurunkan kecemasan menghadapi Persalinan. STIKES PKU Muhammadiyah Surakarta, 1, 262-270.

Zainuddin, A. F. (2014). Seft Total Soution Healing, Happiness, Success, Greatness: Sefter Handbook: Seft Corporation. Afzan Publishing.

\section{UCAPAN TERIMA KASIH}

Ucapan terima kami tujukan kepada Kementerian Pendidikan, Kebudayaan Riset dan Teknologi Republik Indonesia, Badan Riset dan Inovasi Nasional beserta Lembaga Layanan Pendidikan Tinggi Wilayah XI yang telah mendukung pembiayaan penelitian ini, dan Sekolah Tinggi Ilmu Kesehatan mutiara Mahakam Samarinda, seluruh responden yang telah terlibat dan juga Klinik Ramlah Parjib Samarinda yang bersedia tempat dalam penelitian ini. 